\title{
NEW EMDENCE FOR THE ENMRONMENTAL KUZNETS CURVE FOR SULPHUR DIOXIDE EMISSIONS: A CASE STUDY OF THE CZECH REPUBLIC
}

\author{
KATARÍNA HERCEGOVÁ ${ }^{1}$, WADIM STRIELKOWSKI ${ }^{2}$ \\ AWT Group ${ }^{1}$, Charles University in Prague ${ }^{2}$, Czech Republic
}

\section{ABSTRACT}

In this paper we test the model explaining the interdependence between the pollutants and the economic development in the Czech Republic. We calculate the relationship known as the Environmental Kuznets Curve $(E K C)$ by estimating the relationship between the environmental pollution expressed by $\mathrm{CO}_{2}$ and $\mathrm{SO}_{2}$ emissions per capita and the GDP per capita for the Czech Republic for the period from 1990 to 2009. Our findings reveal that the Environmental Kuznets Curve hypothesis for the Czech Republic holds in the case of estimating the inter-dependence between GDP per capita and sulphur dioxide.

\section{JEL CLASSIFICATION \& KEYWORDS}

- C70 - D62 - 013 - Q20 | Environmental Kuznets Curve - Environmental economics $\approx \mathrm{CO}_{2} \backsim \mathrm{SO}_{2}$ emissions $\approx$ Economic development $\approx$ Czech Republic

\section{INTRODUCTION}

In this paper we set up the prerequisites for the mode explaining the interdependence between the pollutants and the economic development of various groups of countries in order to estimate correlation between various factors leading to pollution.

We start with calculating the relationship known as the Environmental Kuznets Curve (EKC) for the Czech Republic and taking into account just one environmental-pressure factor on the left-hand side: carbon dioxide or sulphur dioxide. The right-hand side of the equation is represented by the GDP per capita. The results of this exercise will lead us to choosing the right emission factor to be tested in the case of the Czech Republic as the new EU Member State sharing the same environmental standards and values.

The first step will be to estimate the relationship between the environmental pollution expressed by $\mathrm{CO}_{2}$ and $\mathrm{SO}_{2}$ emissions per capita and the GDP per capita for the Czech Republic for the period from 1990 to 2009.

The second step will be to detect what economic, geographic and demographic factors represented by the unemployment level, GDP per capita, environmental protection investments, population density, the amount of agriculture and forest area and the number of internet users have an impact on the level of pollution in the Czech Republic. The philosophy of the model itself and the methodological occurrence can be graphically presented on the following diagram (Figure 1).

Theoretical framework of the Environmental Kuznets Curve

The environmental Kuznets curve is an inverted-U relationship between environmental quality and economic development ${ }^{1}$. The theory of EKC suggests that the intensity of the per capita environmental impacts of production falls

1 Kuznets's name was apparently attached to the curve because of its resemblance to Simon Kuznets's concept (1955) between income inequality and development.

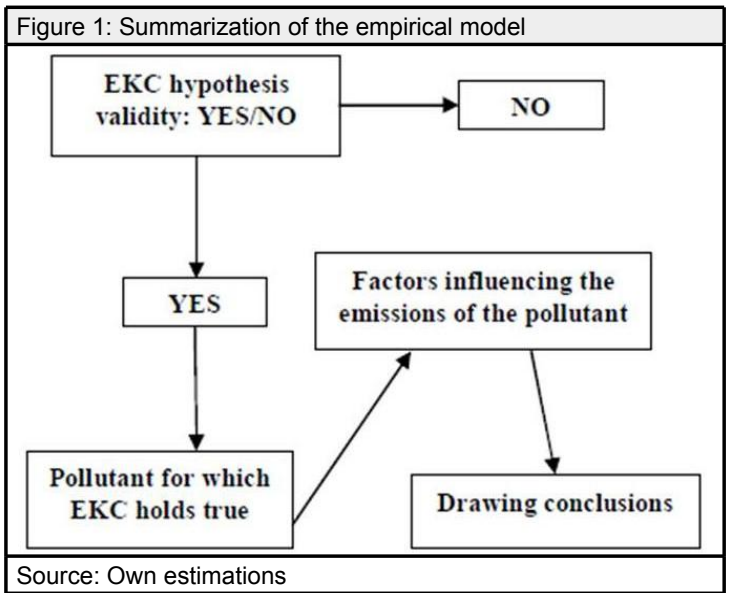

after per capita income passes certain threshold level. It is usually stated that the environment is an income-elastic commodity (Bimonte, 2002). In the first stage of industrialisation, pollution and environmental degradation in the environmental Kuznets curve world grows rapidly because people are more interested in jobs and income than clean air and water, communities are too poor to occupy themselves with the environmental issues and environmental regulation is correspondingly weak. In other words, in the first part of the EKC, environment may be supposed to be an obstacle for economic growth, and therefore growth has a negative effect on environmental quality. Moreover, there is empirical evidence showing a positive feedback between poverty and environmental degradation (Perrings, 1995).

However, the situation changes as income rises. Leading industrial sectors become cleaner due to new technologies and environmental investment, people value the environment more highly, and regulatory institutions become more effective. Beyond some level of income per capita, which varies among different indicators of environmental degradation, economic growth leads to environmental improvement. However, it still remains unclear why environmental quality increases when income exceeds a certain threshold level (Bimonte, 2002). The fundamental implication of this theory is that economic growth may be seen as favouring environmental protection ${ }^{2}$. This is contrary to the general idea that economic growth leads to environmental degradation. This idea reflects the "scale effect". In other words, if there were no changes in the structure of the economy or technology used pure growth in the scale of the economy would result in a proportional growth in pollution and other environmental damages. On

2 The idea that economic growth is necessary in order to environmental quality to be maintained or even improved is an essential part of the sustainable development argument propagated by the World Commission on Environment and Development in "Our Common Future". 
the other hand, the idea behind the EKC model is that "at higher levels of development, structural change towards information-intensive industries and services, coupled with increased environmental awareness, enforcement of environmental regulations, better technology and higher environmental expenditures, results in levelling off and gradual decline of environmental degradation" (Panayotou, 1993). At higher levels of development, environmental protection and expenditure starts to rise because social preferences shift away from private to public goods. We can conclude that from a certain point, due to either necessity (environment becomes a "resource" that has to be taken into consideration in order to grow further) or higher level of participation (information accessibility, better level of education, and more equitable income distribution) economic growth stimulates environmental improvements.

Many econometricians have generally accepted the basic premises of the model and focused on measuring its parameters. Their regressions, typically fitted to crosssectional observations across countries or regions, suggest that air and water pollution increase with development until per capita income reaches a range of $\$ 5000$ to $\$ 8000$. When income rises beyond that level, pollution starts to decline, as shown in the "conventional EKC" line in Figure 2 below.

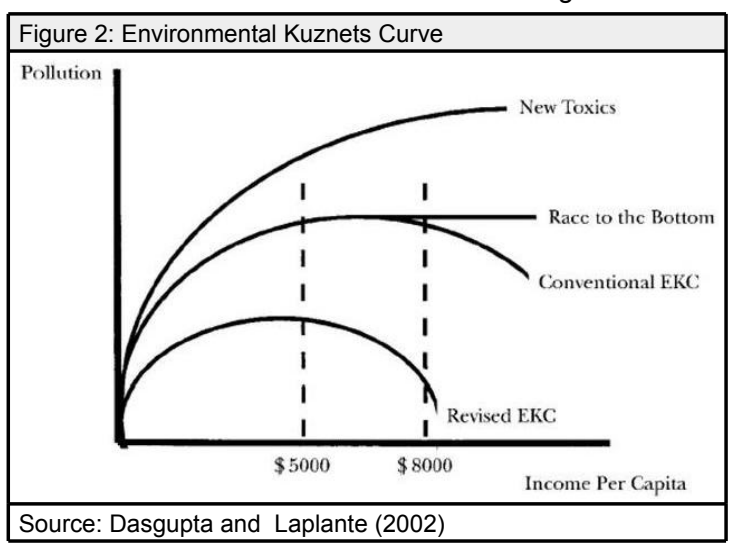

There are, however, many critics of the concept of "conventional EKC". Some of them argue that crosssectional evidence does not reflect the dynamics of the process. They maintain that even if the EKC relationship existed in the past, it is not likely to exist in the future because of the pressures placed on the environmental regulation by global competition. Over time there will be no threshold level, where the environmental quality begins to rise, and the curve will rise to a horizontal line at maximum existing pollution levels. This is case called "race to the bottom" (see Figure 2). In this case, relatively high environmental standards in developed countries impose high costs on polluters. And there is a concern of moving the most polluting firms to developing countries, where there is great unemployment, people have low incomes and environmental regulations are weak or they do not even exist. In addition, the capital outflows might force the governments in developed countries to begin relaxing their environmental standards. So the environmental Kuznets curve flattens and rises towards the highest existing level of pollution.

Other pessimistic approach is that, even if some pollutants are reduced over time with increasing income, there are still newly creating unregulated and potentially toxic pollutants. Thus, the overall environmental pollution may rise, even if certain sources of pollution are reduced, as shown by the "new toxics" line in Figure 2.
However, Dasgupta et al (1996) claim that there is not much empirical research underlying the race to the bottom and new toxic scenarios. In their view, recent empirical work suggests that the curve is actually dropping and shifting to the left as shown by the "revised EKC". This implies that the pollution starts to fall at lower levels of income and economic growth generates less pollution in the early stages of industrialisation compared to the "conventional EKC".

Many empirical studies test the environmental Kuznets curve model. The typical approach is to regress crosscountry data for ambient air and water quality on various specifications of income per capita.

Empirical researchers are far from agreement that the EKC provides a good fit to the available data, even for conventional pollutants. For example, Stern (1998) claims that the evidence for the inverted-U relationship applies only to a subset of environmental measures, e.g. air pollutants such as sulphur dioxide or suspended particulates. On the other hand, Grossman and Krueger (1993) argue that suspended particulates decline monotonically with income and Stern et al. (1998) find that sulphur emissions increase through the existing income range. As regards the water pollution, the results are quite similar, i.e. there is no clear evidence that EKC holds true for certain pollutants.

The problem is also that data is scarce for many pollutants in many countries, not just in developing ones. For this reason, for example, we can just estimate the EKC's shape for toxic pollutants.

There are, however, several problems with environmental Kuznets curve. The first is that the inverted-U relationship is not observed for all types of pollutant. While it has been observed for pollutants with local and recent effect, it tends not to be observed for transboundary ${ }^{3}$ pollutants, where is only little local incentive to internalise the negative externality, or those whose effect will be felt in the future.

The second problem is that the positive implications of economic growth to environmental quality have caused some authors to claim that only economic growth is necessary. Beckerman (1992) maintains that the surest way to improve the environment is to become rich. In this point of view, problems of environmental degradation are only temporary, because economic growth together with technological innovation will solve them in time. But behind this idea, there is a strong assumption that technological innovations will always come just in time. Arrow et al. (1995) argue that there is no reason to believe that the relationship linking income and environmental quality is automatic, and there is no evidence showing that economic growth is a perfect substitute for environmental policy.

Since environmental performance varies among countries, it is possible that also additional variables, others than income per capita, may influence the environmental performance of a country (Bimonte, 2002). For example, economic and social policy may have a great influence on determining the emergence of the downward slopping part of the EKC (Grossman and Krueger, 1995).

Empirical testing of EKC: a case of the Czech Republic

We start with estimating the relationship between the pollutant and the GDP level using per capita estimates of carbon dioxide $\left(\mathrm{CO}_{2}\right)$, sulphur dioxide $\left(\mathrm{SO}_{2}\right)$, and GDP. We estimate the equation by ordinary least squares method.

${ }^{3} \mathrm{~A}$ transboundary impact can be defined as any significant adverse effect on the environment that occurs across the borders of different states. 
The regression model can be formally expressed in the following way:

$$
\log (E / P)=\alpha+\beta^{\star} \log (G D P / P)^{2}+u
$$

where $\mathrm{E}$ is emissions $\left(\mathrm{CO}_{2}\right.$ and $\left.\mathrm{SO}_{2}\right), \mathrm{P}$ is population and log indicates the logarithmic function. The first term on the RHS $(\alpha)$ is the intercept parameter.

The earliest EKCs were simple quadratic functions of the levels of income. The shape of environmental Kuznets curve clearly gives us a message that we are likely to deal with an inverted U-shaped (parabola function, which is expresses as: $y=x^{2}$ ) relationship. Thus, to test the parabola-shaped curve, we will put the logarithm of the independent variable (here the log of GDP per capita) into the powers of 2.

The use of logarithms is explained by the fact that we are trying to estimate the non-linear relationship, the use of logarithms for this purpose is defended for instance in Maddala (1992). Moreover, economic activity implies the use of resources and, by the laws of thermodynamics, the use of resources implies the production of waste. Thus, we should not allow levels of dependent and independent variables to become zero or negative. This restriction can be applied by using a logarithmic dependent variable.

Let us estimate the EKC relationship for the case of the Czech Republic. For our model we use the data for the period from 1990 to 2009. The data are retrieved from the Czech Statistical Office (2011) and the World Bank Development Indicators database (2011). GDP per capita expressed in constant US\$ per person is the independent variable and the pollutant per capita is the dependent variable. The Czech Republic is also at the advanced stage of economic development. Moreover, the environmental protection policy has been largely influenced by the EU environmental policy regulations. Thus, we again assume a negative relationship between the decreasing value of pollutants per capita and the increasing value of GDP per capita.

Let us test the two basic relationships expressed in equation of model set up in (1). We get the following outcome (Table 1).

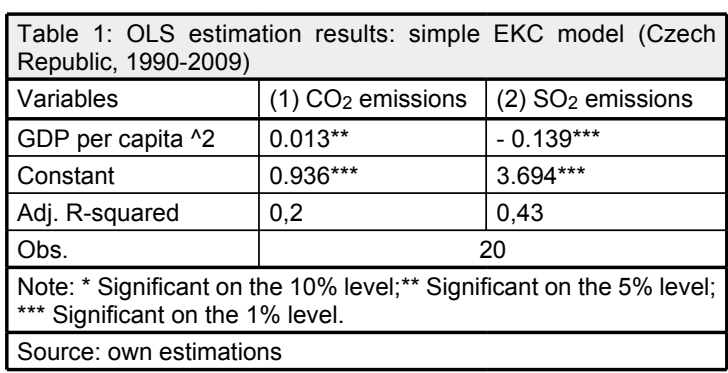

The results show that in the case of the Czech Republic the EKC hypothesis holds true for the $\mathrm{SO}_{2}$ emissions only. The coefficient of the $\mathrm{CO}_{2}$ is positive and highly significant. Let us verify these results using the extended model for testing pollutants' emissions. The model can be presented in the following way:

$$
\begin{gathered}
\log (\mathrm{CO} 2, \mathrm{SO} 2)=\beta 1 \log \text { UNEMPL }+\beta 2 \log \text { GDP }+ \\
\beta 3 \log \text { INVEST + } \beta 4 \log \text { POPDNST }+\beta 5 \log \text { AGRAREA } \\
+\beta 6 \log \text { INTERNET + } \beta 7 \log \text { FOREST }
\end{gathered}
$$

where $\mathrm{CO}_{2}$ (or $\mathrm{SO}_{2}$ ) is the dependent variable, expressed as the carbon dioxide (or sulphur dioxide) emissions per capita in the Czech Republic expressed in metric tones of pollutant per capita. The explanatory variables used in the model are the following:

- UNEMPL - indicates the level of total unemployment in the Czech Republic expressed as a percent of total labour force,

- GDP - level of gross domestic product per capita expressed in constant US\$ per person,

- INVEST - expenditure on environmental protection investment expressed in millions of CZK in current prices,

- POPDNST - population density in the Czech Republic measured in number of people per square kilometre,

- AGRAREA - agricultural area in the Czech Republic measured in thousands hectares used in agriculture or for the sub-agricultural use,

- INTERNET - number of Internet users in the Czech Republic,

- FOREST - total land area covered by the tree species in the Czech Republic expressed in hectares.

These variables can be divided into several clusters. We can depict the nature of the independent variables in the following table (Table 2):

Table 2: Independent variables: the model for the factors leading to decreasing of the environmental pollution in the Czech Republic

\begin{tabular}{|l|l|l|}
\hline Variable & Classification & Impact (- /+ sign) \\
\hline Unemployment & Economic & - \\
\cline { 1 - 1 } GDP per capita & & - \\
\hline Environmental investments & Environmental & - \\
\hline Population density & Demographic & + \\
\cline { 1 - 1 } Internet users & & - \\
\hline Agricultural areas & \multirow{2}{*}{ Geographical } & + \\
\cline { 1 - 1 } & & - \\
\hline Forested areas & & \\
\hline \multirow{2}{*}{ Source: own estimations } & &
\end{tabular}

The signs of the independent variables are presented in the table above. We assume that each of the variables has negative or positive impact on the dependent variable - the pollutant factor represented by the $\mathrm{CO}_{2}$ or $\mathrm{SO}_{2}$ per capita.

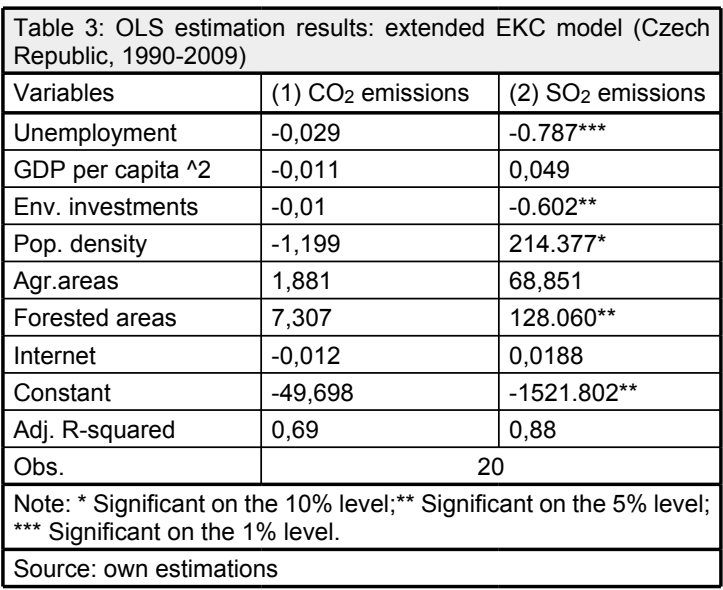

Although in both cases adjusted R-squared are quite high, the results show that the coefficients for $\mathrm{CO}_{2}$ emissions do not behave as expected. Moreover, the coefficients for $\mathrm{CO}_{2}$ estimates are non-significant. This allows us to drop the $\mathrm{CO}_{2}$ model and focus on $\mathrm{SO}_{2}$ model only. We abridge the model defined in (2) using backwards stepwise regression. Backwards stepwise regression represents the approach 
that often applied in multilinear regression. It represents a common task to determine the "best" set of independent variables to use in the fit. Backward step regression used here starts with the initial model that contains all the independent variables. Then one variable is deleted at each stage (at first the variable that causes the smallest drop in adjusted R-squared is dropped) until the best model is reached. The results are shown in Table 4.

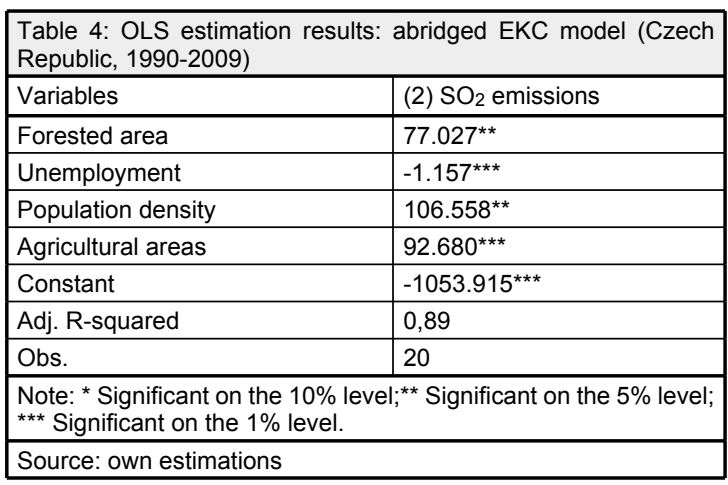

As regards the impact of dependent variables on the $\mathrm{SO}_{2}$ emissions, the beta coefficient is negative for the unemployment rate. In other words, as this variable increases, environmental quality will improve. Its value is higher than 1 , so its impact on $\mathrm{SO}_{2}$ emissions is more than proportional.

The forested areas, agricultural areas and population density all have positive and significant effect of sulphur dioxide emission in the Czech Republic. While the results are logical for the latter two variables, the positive coefficient of the forest areas is quite surprising for the former one. One of the possible explanations can be that the forests management has for a long time been in the hands of the state and the environmentally-friendly approach in managing the forests has started to emerge throughout the 1990s. However, there is still more to improve in that direction. We assumed that the beta coefficients for the population density and the agricultural area are positive. The impact of the agricultural area in the Czech Republic is smaller compared to the population density variable, where the beta coefficient is higher than one, which means that there is more than a proportional impact on the sulphur dioxide emissions.

Thus, the model for the Czech Republic clearly shows that geographical, economic and demographic factors, represented by forest and agricultural areas, unemployment rate and population density are of a great importance for fighting with significant pollution factors.

\section{Conclusion}

Environmental Kuznets curve hypothesis seems to have its grounds in the cases tested above. We built up a model to test which factors influence the pollutant emissions for Czech Republic. It seems that some form of a relationship or inter-dependence that reminds the EKC truly exists for our test and the curve is valid for certain observations of sulphur dioxide emissions (our hypothesis is rejected for carbon dioxide). The most possible reason for this is that the $\mathrm{CO}_{2}$ is harming the environment at the global level, so there is not so high pressure to internalise the externalities like it is in the case of sulphur dioxide emissions. This fact is also consistent with conclusion from the literature that the EKC relationship does not exist and that indicators of environmental degradation are more likely to rise monotonically in income.
Our findings for the Czech Republic show that there are several explanatory variables with the most significant impact: unemployment rate, forest and agricultural areas, and population density.

\section{REFERENCES}

1. Arrow et al. (1995): Economic growth, carrying capacity, and the environment, in: Science 268, pp.520-521.

2. Beckerman, W. (1992): Economic growth and the environment. Whose growth? Whose environment? In: World Development, 20, pp.481-496.

3. Bimonte, S. (2002): Information access, income distribution, and the Environmental Kuznets Curve, in: Ecological Economics 41/2002, pp. $145-156$.

4. Czech Statistical Office (2011). Statistics retrieved from: http://www.czso.cz

5. Dasgupta, P. (1996): The economics of the environment. The development economics research programme (73), London School of Economics, pp.

6. Dasgupta, S. et al., (2002): Confronting the Environmental Kuznets curve, in: Journal of Economic perspectives, Volume 16, Number 1/Winter 2002, pp. 147-168.

7. Grossman, G., Krueger, A. (1993): Environmental Impacts of the North American Free Trade Government, in: Garber, P., (ed.): The U.S.-Mexico Free Trade Agreement, Cambridge, pp. 13-56.

8. Grossman, G., Krueger, A. (1995): Economic growth and the environment, in: Quarterly Journal of Economics 110, pp. 353-378.

9. Kuznets, S. (1955): Economic growth and income inequality, in: American Economic Review 45, pp. 1-28.

10. Maddala, G.S. (2001): Introduction to econometrics, Third edition, John Wiley \& Sons Ltd.

11. Panayotou, T. (1993): Empirical Tests and Policy Analysis of Environmental Degradation at Different Stages of Economic Development, Working Paper WP238, Technology and Employment Programme, International Labour Office, Geneva.

12. Panayotou, T. (1993): Green Markets: The Economics of Sustainable Development, Institute for Contemporary Studies Press., pp.

13. Perman, R., Stern, D.I. (2003): Evidence from panel unit root and cointegration tests that the environmental Kuznets curve does not exist, in: Australian Journal of Agricultural and Resource Economics Vol. 47, pp.

14. Perrings, C. (1995): Sustainable livelihoods and environmentally sound technology: theoretical and conceptual approaches, in: Ahmed, I., Doeleman, J.A. (Eds.): Beyond Rio. The Environment Crisis and Sustainable Livelihoods in the Third World, MacMillan Press Ltd.

15. Stern, D.I. (1997): Limits to substitution and irreversibility in production and consumption: a neoclassical interpretation of ecological economics, in: Ecological Economics 22, pp. 197-215.

16. Stern, D.I. (1998): Progress on the Environmental Kuznets Curve?, in: Environment and Development Economics. 3:2, pp.175198.

17. Stern, D.I. (2003): The Environmental Kuznets Curve, International Society for Ecological Economics, pp. 325-347

18. Stern, D.I. et al., (1998): Is there an environmental Kuznets curve for sulfur?, Working papers in Ecological Economics, 9804, Australian National University, Canberra.

19. World Bank (2011): World Development Indicators \& Global Development Finance. Available at: http://databank.worldbank.org/ ddp/home. do? $\mathrm{CNO}=2 \&$ Step $=12 \& \mathrm{dd}=4$

20. World Commission on Environment and Development (1987): Our Common future, Oxford University Press 